\title{
Welcome to the new associate Editor-in-Chief of memo
}

\author{
Wolfgang Hilbe $\cdot$ Waltraud Radlherr
}

Received: 14 June 2016 / Accepted: 14 June 2016 / Published online: 31 August 2016

(C) Springer-Verlag Wien 2016

Being in its ninth year now, memo is ready for the next step. Thus, it was decided to call for an associate Editor-in-Chief. At the last Editorial Board (EB) meeting distinguished candidates were proposed and we are now very proud to introduce Prof. Rupert Bartsch. He completed his education at the Medical University of Vienna and is experienced in various fields of oncology-first of all breast cancer, gynecological cancer, and colorectal cancer. Prof. Bartsch has also taken part in various internationally based clinical trials and studies. As the new associate Editor-in-Chief, he is going to represent the next generation of clinical scientists opening the view to the requirements of our younger colleagues. Furthermore, his research work at the university is an ideal academic link between clinical and basic research.

Now we want to pass on the word to Rupert Bartsch himself.

Wolfgang Hilbe, Editor-in-Chief Waltraud Radlherr, memo secretary

Conflict of interest W. Hilbe and W. Radlherr declare that they have no competing interests.

W. Hilbe, MD ( $\square)$

Wilhelminenspital, Montleartstrasse 37, 1160 Vienna,

Austria

wolfgang.hilbe@meduniwien.ac.at

W. Radlherr

Speckkarstrasse 27, 6068 Mils, Austria 